\title{
Integrating Writing Modes into Speaking Tasks
}

\author{
Maria Hidayati, Nova Ariani \\ Universitas Negeri Malang \\ maria.hidayati.fs@um.ac.id \\ novayatierra@gmail.com
}

\begin{abstract}
Writing and speaking serve similar purposes in terms of communicating our needs, establishing and maintaining social relationships. Both skills need to be generated by the learners, yet the medium used to convey the message is different. Bailey (2006) refers the medium used to convey the message to modality in which speaking is the productive oral skill meanwhile writing is the productive written skill. Although, both employ different medium, it is possible to integrate writing modes into speaking tasks as what we have applied in our Speaking Classes. Teaching Speaking for Academic Purposes subject to the fourth semester students encourages us to let them make use of what they have learned in Writing courses from their previous semesters. Speaking for Academic Purposes is the advanced level Speaking course because the students need to employ important language functions in presenting current issues, panel discussion and debates (Department of English Catalogue, 2016). To achieve the objective of the course, the activities designed in our classes are to equip the students with abilities to express their opinions, give persuasion and suggestions, compare and contrast ideas, state and justify opinion. Therefore, this paper is to describe the result of integrating writing modes into speaking tasks by adhering to writing organization such as example, problem-solution, persuasive and argumentative modes. The description is managed into two folds: (1) the description of the activities conducted in Speaking classes; and (2) the students' responses on the activities designed in the classroom. This paper concludes that it is possible to align what the students have learned in Writing classes into Speaking Classes.
\end{abstract}

Keywords: Writing modes, Speaking tasks, alignment

\section{INTRODUCTION}

Writing and speaking are two productive language skills which require the learners to communicate their needs as a means of establishing and maintaining social relationships. One way to learn those productive skills is through meaningfocused output where the learner's attention is on conveying ideas and messages to another person. However, knowing and understanding the language and producing it sometimes do not reciprocal. Learning how to write in a second language is one of the challenging aspects in second language learning (Hyland, 2003). With the development of approaches in teaching writing, the purposes of teaching writing have also been evolving. Here, we have attempted to list a number of purposes which are in line with our study. Hyland (2003) mentioned three purposes of teaching writing, they are: 1) to distinguish different genres and to write them more effectively by doing a careful study of their structures; 2) to foster creativity while acknowledging the ways language is conventionally used to express meaning; and 3) to employ conventional patterns and the circumstances where they can change them. In relation to those, Harmer (1998) listed the reasons in teaching writing to students of English as a foreign language. They are reinforcement, language development, learning style, and writing as a skill in its own right. While Hyland focuses on the importance of genre-based teaching, Harmer encompasses the pedagogical aspects within the teaching of writing.

When it comes to speaking, Harmer (2007) addresses the characteristics of spoken English and the idea of genre. He mentioned the purposes of teaching speaking as follows: 1) to speak in a range of different genres and situations; 2) to be able to use a range of conventional and conversational repair strategies; and 3) to be able to survive in typical functional exchanges. In line with Harmer, Thornbury (2005) states that by teaching speaking, students are intended to have: 1) awareness; students need to be made aware of features of the target knowledge base; 2) appropriation; students need to integrate those features into their existing knowledge base; and 3 ) autonomy; students need to develop the capacity to mobilize those features under real-time conditions and unassisted.

Students learning English might face problems in using and producing language in spoken forms as indicated by some previous studies in the context of English as a foreign language, such as by Fauzan $(2014,2016)$ and Maulana, Daud and Heriansyah (2016). In his two studies, Fauzan indicated that students do not want to speak English because they are too shy to talk in English, they are afraid of making mistakes or their friends will laugh at them, and they are anxious because the teacher always gave critics or correction. In the next two years, Fauzan also showed that students had problems to talk spontaneously and to stimulate their creativity in exploring the language. Based on the data gathered from the interview with the students and the questionnaires, Maulana, et al (2016) found that the problems mostly faced by students in learning speaking skill are lack of vocabulary, poor pronunciation, less confidence to speak and being afraid of making errors when speaking. Similarly, problems are also encountered by students at Department of English in their fourth semester in terms of exploring the language and organizing ideas into a good and well-structured spoken discourse and forms.

SAP is an advanced level of Speaking courses for Department of English students, Universitas Negeri Malang. Offered in the fourth semester, this course is designed to develop students' ability to use important language functions in presenting current issues, panel discussions and debates 
(Department of English Catalogue, 2016). Speaking as a part of work or academic study has several important features (Brown, 1981) in Nation and Newton (2009): "It is influenced by written language. Often it will involve speaking from notes and will involve academic vocabulary". Moreover, formal talks need to be scripted and learners need the chance to prepare it well to develop better spoken presentation. Therefore, good preparation for a talk can involve group work activities to gather and elaborate the information that will be presented. Here, the students can look up into the writing modes which had been learned in the previous semester; that is Essay Writing course. This course develops students' ability to write expository essays using different methods of development: logical division of ideas, chronological order, comparison and contrast, cause and effect, and classification (Department of English Catalogue, 2016). When students face difficulties in formal speaking course, they may have little subject knowledge on particular topic that might be new for them. Thus, a high level of familiarity with the content of a talk is likely to lead to quality in other aspects such as the presentation, formal correctness and awareness of audience (Nation \& Newton, 2009).

The similar features of speaking and writing leads to implications for teaching. Thus this paper aims to describe the result of integrating writing modes into speaking tasks by adhering to writing organization. Therefore, this study is intended to describe kinds of activities in speaking classes and students' responses in integrating writing types into speaking tasks.

\section{METHOD}

This study employed descriptive qualitative method. Best (1970) in Cohen, Manion, and Morrison (2000, p.205) mentions that descriptive research is concerned with how, what or what exists is related to some preceding event that has influenced or affected a present condition or event'. Therefore, this study attempts to describe kinds of activities by integrating writing modes into speaking tasks and to show the students' responses in the implementation of speaking tasks.

This study collected students' responses from two Speaking for Academic Purpose (SAP) classes. The data were gathered through questionnaires to 46 (forty six) respondents and there were 22 (twenty two) students responded to the questionnaires. The researcher selected and implemented activities from Gammidge (2004) and distributed questionnaires via Google form. Google form was chosen as the medium to distribute the questionnaire as it has several advantages in comparison to a paper questionnaire (Watt, 1997; Dillman et al, 1999; Dilman and Bowker, 2000, Roztocki and Lahri, 2000 in Cohen et al 2000) such as reducing costs and time to distribute, gather and process data, providing a wider population to be accessed, allowing respondents to complete the questionnaire from home and at a time to suit themselves.

The questionnaire consists of 15 questions. The first four questions asks the students to write about their memories on essay writing in their previous semester. Some other questions addressed their responses on taking SAP class while the remaining questions explored on their opinions when it comes to the selected activities for SAP class.

\section{FINDINGS AND DISCUSSION}

This study attempted to describe the result of integrating writing modes into speaking tasks designed for students taking SAP classes. This section describes the result of this study which were divided into three parts: (1) the description of writing class; (2) the kinds of activities in speaking classes and (3) the students' responses and reasons in integrating writing modes into speaking tasks.

\section{The Description of Writing Class}

This study sought to gather students' responses on activities designed by integrating writing modes into speaking tasks, it would be fruitful to describe the writing classes, as the basis of following speaking tasks. The participants involved in this study were students taking SAP in their fourth semester who had passed Essay Writing classes. Students taking Essay Writing are expected to be able to write expository essays using different methods of development: logical division of ideas, chronological order, comparison and contrast, cause and effect and classification (Department of English Catalogue, 2016). In order to achieve those learning outcomes, students were introduced with many kinds of writing modes, such as example essay, problem solving, comparison-contrast, persuasive, cause and effect and also classification. The students were aware of the objective of taking Essay Writing courses as indicated in their responses in answering the questionnaires distributed in Google form:

R1: To prepare the students in writing about more formal topic so that the students will be able to prepare their thesis.

R3: The students are able to write kinds of essay, such as compare - contrast essay, persuasive essay, etc. Also the students are able to understand the structure of essays.

R4: To develop our skill and critical thinking skill in developing a well-structured, coherent and cohesive essay.

R15: The students will be able to write a wellorganized essay that offers a clear thesis and support it by supporting sentences.

The students' responses indicate that they realized the objectives of Essay Writing were to write several types of essays. The responses also shows that they were aware of different organization and text structure in writing different kinds of essay.

\section{Kinds of Activities in Speaking Classes}

SAP is the advanced level of the three speaking courses offered in Department of English curriculum; those courses are: Speaking for Formal Interactions, Speaking for Informal Interactions and Speaking for Academic Purposes. The course objective of SAP is for students to use important language 
functions in presenting current issues, panel discussion and debates (Department of English Catalogue, 2016). Considering the course objective, this advanced level of speaking course is intended to improve students' formal speech. Therefore, it is the teachers' job to equip them with some language functions and some insights to perform in delivering formal speech. This is in line with what has been discussed by Wallace, Stariha and Walberg (2004) in the way that students need to be provided insights on how to organize their ideas in various ways sequentially, chronologically and thematically. In addition, providing them some activities to practice their speech on problems and solutions, causes and effects, similarities and differences becomes the consideration in designing speaking tasks. Therefore, there are four kinds of speaking activities consisting of three activities adapted from Gammidge (2004) and one activity as text modelling of writing organization. The activities designed in speaking tasks are "Family Values", "What are Friends for?", and A messy Home Means a Messy Mind". The elaboration and description of each task are as follows.

\section{a. Family Values}

This activity was adapted from Gammidge (2004) which focuses on the activity to express opinions, to agree and to disagree. The worksheet of this activity can be seen in Figure 1.

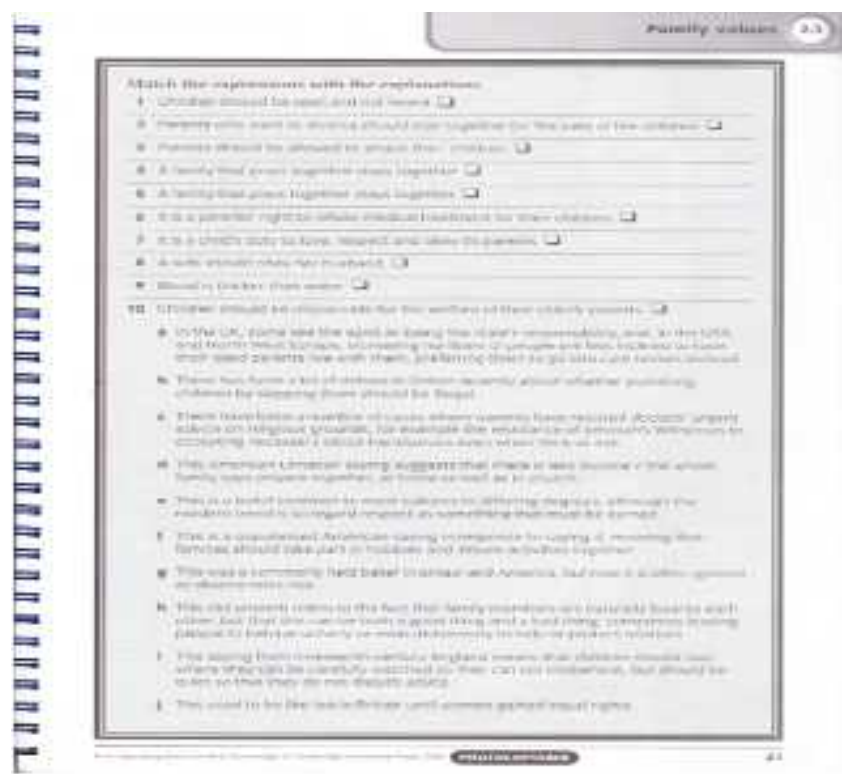

Figure 1. The Worksheet of Family Values

As can be seen in Figure 1, the topic of this activity is family rights and duties whose activity type is for ranking task and having discussion. The activity in using this worksheet is intended to trigger the students' understanding in formulating thesis statements in writing essays. The activities were conducted in the following steps:

- Distributing the worksheet to the students and asking them to match the expressions with the explanations provided in the worksheet done in pairs.
- Conducting a classroom discussion on the students' answers in matching the expressions with the explanations.

- Choosing one expression to agree with and one expression to disagree with.

- Introducing and linking with the way how students should formulate a thesis statement in essay writing.

- Asking the students to give reasons on their chosen expressions.

\section{b. What Are Friends For?}

Figure 2 shows the worksheet of the activity of "What Are Friends For?" which focuses on expressing opinions, giving explanations, agreeing and disagreeing.

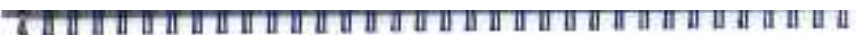

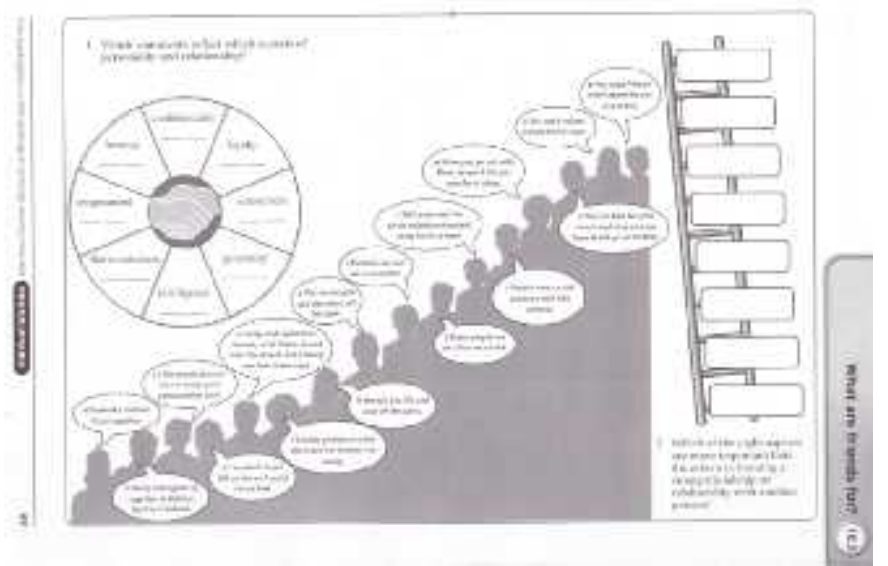

Figure 2: The Worksheet of "What are Friends for?"

The intended activity for this worksheet is group discussion and ranking. Yet, the worksheet was delivered with a little modification based on the following stages:

- Matching the comments with the aspects of personality and relationship.

- Discussing the students' answers

- $\quad$ Asking the students to choose the most important and the least important of personality in having friendship

- Asking them to relate their choice with their personal experience as an example.

\section{c. A Messy Home Means A Messy Mind}

The topic in this activity is related to the ancient art of Feng Shui which focuses on discussing and evaluating ideas and also making suggestions. Figure 3 shows the worksheet used in SAP to introduce language expressions to evaluate ideas and make suggestions. 


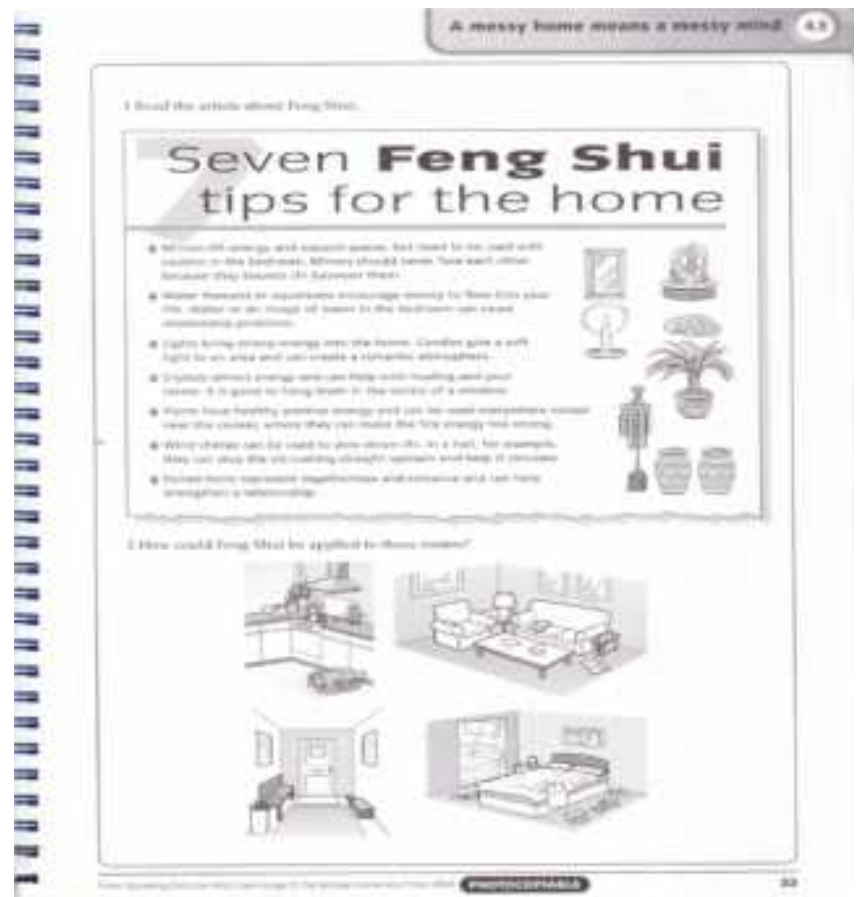

Figure 3: The Worksheet on A Messy Home Means A Messy Mind

The delivery of this worksheet in speaking classes was as follows:

- $\quad$ Playing a video on Feng Shui

- Asking the students' opinions on Feng Shui shown from the video

- Distributing the worksheet

- Discussing the Feng Shui tips for the home

- Providing language expressions to evaluate ideas and make suggestions

- $\quad$ Looking at the pictures on the worksheet and asking students to provide possible suggestions based on Feng Shui tips.

\section{d. Text Modelling}

After providing some speaking tasks as a means to equip students with language expressions and language functions, text modeling was used to elicit the students' schemata on writing genre. By showing and asking the students to deconstruct and evaluate some examples on writing texts (Figure 4), students needed to be made aware of the way their formal speech was organized.
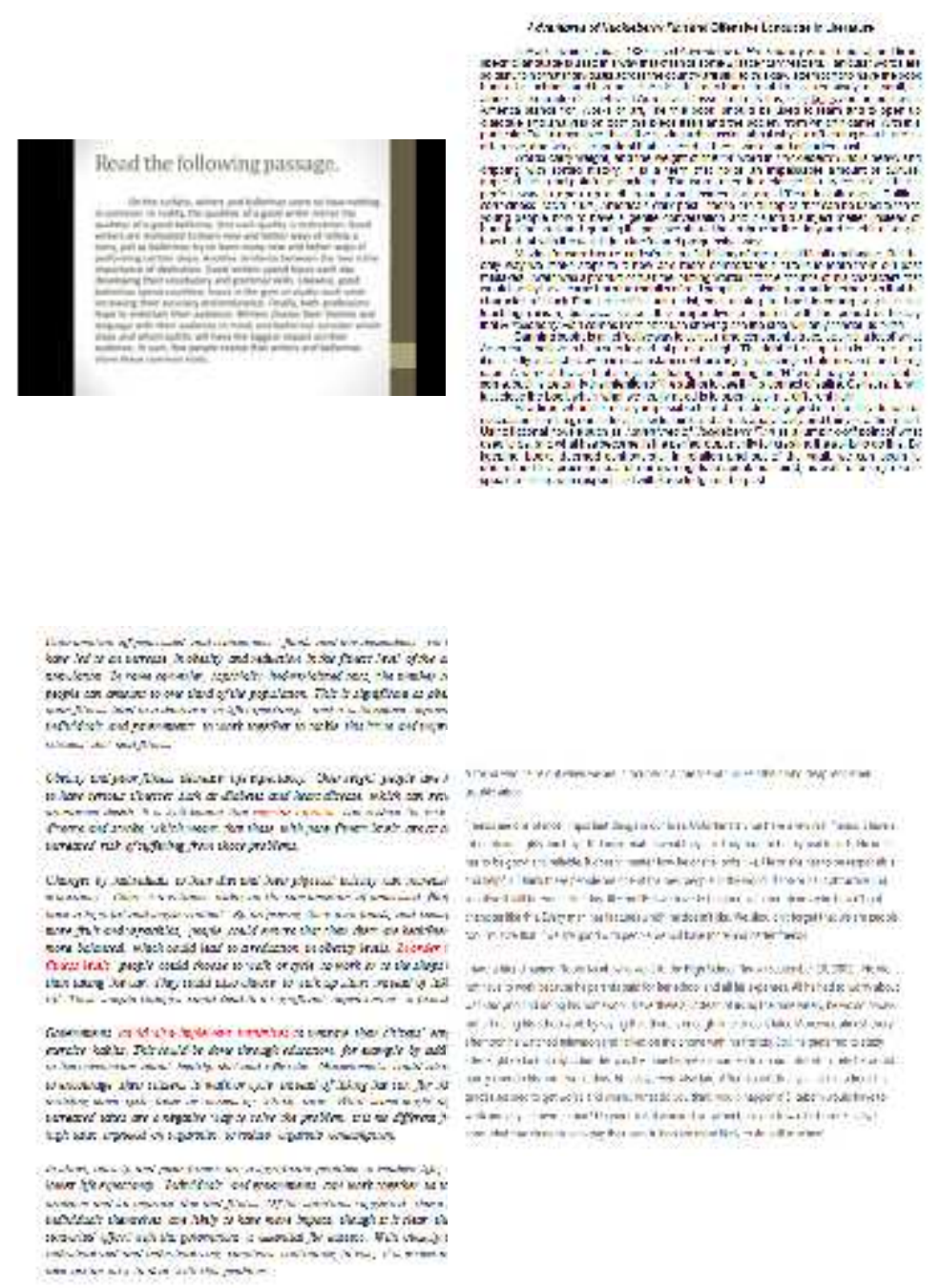

Figure 4. Some Text Types Used in Text Modeling

Figure 4 shows several types of texts used in text modeling activities. Those texts were organized based on comparison and contrast, problem-solution, example and persuasive essays. The activities conducted in this speaking task were as follows:

- $\quad$ Showing the students various kinds of essays.

- Relating those essays with what they had learned in Essay Writing

- Asking the students to identify the text structure in each essay by deconstructing and evaluating the texts.

\section{Students' Responses and Reasons}

The data were from the students' responses on speaking tasks collected through questionnaires delivered via Google form. There are 15 questions designed, and questions 8 to 15 are asking the students' responses on types of activities designed in SAP classes which can be seen in Figure 5. The questionnaires asks whether the activity in "Family values" give the students chance to express their opinions; whether the 
activity in "What Are Friends For?" provide them chance to give explanation and justify their opinions; and whether the activity in "A Messy Home Means A Messy Mind" provide them chance to give suggestions and to persuade others; and whether the activity of discussing some examples on types of essay help them employ language functions in presenting current issues, having panel discussion and debates. In addition, students were also asked to provide their reasons.

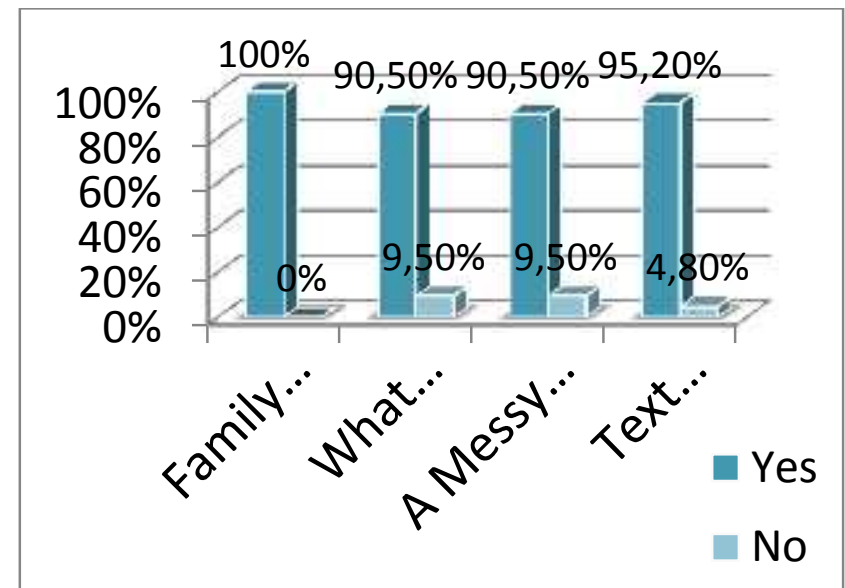

Figure 5. Students' Responses on Speaking Tasks

From 44 responses, 22 were responses analysed. From the selected speaking tasks, all students agree that "Family Values" gave chance and opportunities to express their opinions. It is in line with the reasons they gave.

\begin{abstract}
"Because that topic is a topic that I have an experience in, so that it becomes easier for me to express my opinion related to this topic"

"Because it allowed me to express what's in my mind about the topic or problem given to me which is about family and also connect it with me"
\end{abstract}

Meanwhile, there are $9.5 \%$ of respondents who do not agree that the activity "What are Friends for?" gave them chance to give explanation and justify their opinions. One of the students responded that he/she forgot what happened in the meeting. Meanwhile, one student states that:

\begin{abstract}
"No, because in my opinion to tell other classmate what kind of a friend we are is too personal subject which is not going to be honestly answered. However, in the terms of learning activities, it was quite good in giving students opportunity to explain."
\end{abstract}

In addition, the rest of the students who agreed on the designed speaking tasks to give explanation and justify their opinions provided responses as follows:

\begin{abstract}
"Because in that activity I was given the chance to publicly state my personal opinion on how we should choose friend and also get feedback from other people."

"It is related to my daily basis and some experiences related to the value have been passed through, so it is easier to get indulged to the topic."
\end{abstract}

The students' responses on the designed speaking task about "A Messy Home Means A Messy Mind" show similar percentages to the activity in "What Are Friends For?". The students responded that it was not easy to give persuasion. The students' reasons on this activity can be seen in the following:
"Because in this session, I am able to express my opinion on what correlation a messy home and a messy mind have. And later, I also can persuade my friends to agree with what I believe."
"Because, the learning material was successfully engage students to be more critical in the terms of giving suggestion"

The speaking tasks on text modelling expose students with language functions and expressions in presenting current issues, having panel discussion and debates. Their responses are as follows:

\begin{abstract}
"Because by discussing some examples of essay, I can think more of how I should develop my speech. And believe me, it works."

"Those essay makes me browse for more information and also using language functions which is similar to the language we use to present issues, argument, or opinion."
\end{abstract}

From the students' responses on the selected speaking tasks, they are aware that the selected speaking tasks implemented in SAP classes are in line with what they have learned in Essay Writing. In presenting and conducting panel discussion and debate, organizing their ideas can be based on structuring their ideas in writing comparison-contrast, example, problemsolution, and persuasive essays. Integrating the writing modes into speaking tasks in the form of selecting and adapting activities helps students to develop their knowledge of language item as has been indicated by Brown and Nation (1997). In addition, as learners of English, students did appropriation as they integrated their knowledge on essay writing into speaking tasks. Furthermore, Harmer (1998) mentions that giving speaking tasks is beneficial in that it gives students 1) rehearsal, 2) feedback, and 3) engagement. Rehearsal allows students to have free discussion, feedback enables teachers to see how well their class is doing and what language problems the students face, and engagement will make students to be highly motivated. 


\section{CONCLUSIONS AND SUGGESTIONS}

Based on the description, explanation and elaboration previously stated, it can be concluded that it is possible to align writing modes into speaking tasks. Adapting some activities from Gammidge (2004) and linking the activities with what the students had learned in previous semester, the students were able to express their opinions, explain and justify their opinions, give suggestions and persuade others. The activities designed help students achieve the learning outcomes of the course that is to help them conduct panel discussion and debates. This study suggests that further studies on finding out the students' improvement on their speaking performances by integrating writing modes into speaking tasks need to be conducted. In addition, other studies on finding out the result of integrating speaking modes into writing tasks should be done.

\section{REFERENCES}

Brown, R.S., \& Nation, P. (1997). Teaching speaking: Suggestions for the classroom. Accessed from http://www.jaltpublications.org/tlt/files/97/jan/speaking.html.

Cohen, L. Manion, L., \& Morrison, K. (2007). Research methods in education (sixth edition). UK: Routledge

Department of English Catalogue. (2016). English department catalogue. Malang: UM Press.

Fauzan, U. (2014). The use of improvisation technique to improve the speaking ability of EFL students. DINAMIKA ILMU, 14 (2).

Fauzan, U. (2016). Enhancing speaking ability of EFL students through debate and peer assessment. EFLJournal, $1(1), 49-57$

Gammidge, M. (2004). Speaking extra. Cambridge: Cambridge University Press.

Harmer, J. (2007). The practice of English language teaching (Fourth Edition). UK: Pearson Longman.

Harmer, J. (1998).How to teach English: An Introduction to the practice of English language teaching. UK: Pearson Longman.

Hyland, K. (2003). Second language writing. Cambridge: Cambridge University Press.

Maulana, R., Daud, B., Heriansyah, H. (2016). Students' views on EFL speaking problems. Proceedings of the First Reciprocal Graduate Research Symposium between University Pendidikan Sultan Idris and Syiah Kuala University, February 26 - 28, 2016, Perak, Malaysia.

Nation, I.S.P., \& Newton, J. (2009). Teaching ESL/EFL listening and speaking. UK: Routledge. Thornbury, S. (2005). How to teach speaking. United Kingdom: Pearson Education Limited. 